\title{
Dietary lysophospholipids supplementation inhibited the activity of lipolytic bacteria in forage with high oil diet: an in vitro study
}

\author{
Hanbeen Kim, ${ }^{1, a}$, Byeongwoo Kim ${ }^{1, a}$, Seongkeun $\mathrm{Cho}^{1}$, Inhyuk Kwon², and Jakyeom Seo ${ }^{1, *}$
}

* Corresponding Author: Jakyeom Seo Tel: +82-55-350-5513, Fax: +82-55-350-5519,

E-mail: jse081@pusan.ac.kr

'Department of Animal Science, Life and Industry Convergence Research Institute, Pusan National

University, Miryang 50463, Korea

2 EASY BIO, Inc., Seoul 06253, Korea

a These authors contributed equally to this study.

ORCID

Hanbeen Kim

https://orcid.org/0000-0003-2803-7318

Byeongwoo Kim

https://orcid.org/0000-0003-3300-0173

Seongkeun Cho

https://orcid.org/0000-0001-9309-2327

Inhyuk Kwon

https://orcid.org/0000-0001-8144-7928

Jakyeom Seo

https://orcid.org/0000-0002-9176-5206

Submitted Oct 31, 2019; Revised Jan 6, 2020; Accepted Jan 22, 2020
Objective: The objective of this study was to evaluate the effects of lysophospholipids (LPL) supplementation on rumen fermentation, degradability, and microbial diversity in forage with high oil diet in an in vitro system.

Methods: Four experimental treatments were used: i) annual ryegrass (CON), ii) $93 \%$ annual ryegrass $+7 \%$ corn oil on a dry matter $(\mathrm{DM})$ basis $(\mathrm{OiL})$, iii) OiL with a low level $(0.08 \%$ of dietary DM) of LPL (LLPL), and iv) OiL with a high level (0.16\% of dietary DM) of LPL (HLPL). An in vitro fermentation experiment was performed using strained rumen fluid for $48 \mathrm{~h}$ incubations. In vitro DM degradability (IVDMD), in vitro neutral detergent fiber degradability, $\mathrm{pH}$, ammonia nitrogen $\left(\mathrm{NH}_{3}-\mathrm{N}\right)$, volatile fatty acid (VFA), and microbial diversity were estimated.

Results: There was no significant change in IVDMD, $\mathrm{pH}, \mathrm{NH}_{3}-\mathrm{N}$, and total VFA production among treatments. The LPL supplementation significantly increased the proportion of butyrate and valerate (Linear effect [Lin], $p=0.004$ and $<0.001$, respectively). The LPL supplementation tended to increase the total bacteria in a linear manner $(p=0.089)$. There were significant decreases in the relative proportions of cellulolytic (Fibrobacter succinogenes and Ruminococcus albus) and lipolytic (Anaerovibrio lipolytica and Butyrivibrio proteoclasticus) bacteria with increasing levels of LPL supplementation (Lin, $\mathrm{p}=0.028,0.006,0.003$, and 0.003, respectively).

Conclusion: The LPL supplementation had antimicrobial effects on several cellulolytic and lipolytic bacteria, with no significant difference in nutrient degradability (DM and neutral detergent fiber) and general bacterial counts, suggesting that LPL supplementation might increase the enzymatic activity of rumen bacteria. Therefore, LPL supplementation may be more effective as an antimicrobial agent rather than as an emulsifier in the rumen.

Keywords: Lysophospholipids; Emulsifier; Feed Additive; Rumen Fermentation; Microbial Diversity

\section{INTRODUCTION}

The addition of a lipid source has been used to increase energy density in cattle diets because of the higher energy content of lipids compared with carbohydrate and protein on a weight basis. Conversely, the use of excessive lipids (6\% to $7 \%$ of the dietary dry matter $[\mathrm{DM}])$ in the ruminant diet might decrease DM intake, which could negate the increased energy density [1].

Lysophospholipids (LPL) are monoacyl-derivatives of phospholipids resulting from the action of phospholipase A1 or A2 [2] and can improve the digestion and absorption of lipids. The LPL has been used as a feed additives to improve the production performance of nonruminant animals and has consistently shown an increase in feed efficiency and nutrient utilization [3-6]. 
In ruminant nutrition, to our knowledge, few studies have investigated the effects of LPL supplementation on ruminants [7-9]. Jenkins et al [7] reported that the addition of phospholipids had different effects on ruminal fermentation characteristics depending upon the source of the LPL with no positive effect on fiber digestion in an in vitro system. However, Sontakke et al [8] observed that supplementation of LPL obtained from rice bran could increase in vitro organic matter (OM) digestibility when $6 \%$ of LPL was supplemented in the diet. Lee et al [9] reported an increase in milk yield and milk components (amounts of protein and lactose in milk) with increasing levels of LPL supplementation $(0.05 \%$ and $0.075 \%$ of dietary DM). Furthermore, emulsifying agents (e.g., non-ionic surfactants) have been reported to improve the enzymatic activities of protease and cellulase in the rumen, even though they are not components of LPL [10].

To our knowledge, no study has investigated the effects of LPL on rumen fermentation in fiber containing a high lipid source, and we questioned whether LPL supplementation could prevent the negative effects resulting from high oil content, such as decreased fiber digestion and volatile fatty acid (VFA) production. This study was conducted to evaluate the effects of LPL supplementation on rumen fermentation characteristics, ruminal degradability, and microbial diversity in a forage-based diet with high oil content in an in vitro system.

\section{MATERIALS AND METHODS}

Animal use and experimental protocols were reviewed and approved by the Animal Research Ethics Committee of Pusan National University (PNU-2019-2239).

\section{Preparation of experimental diets and chemical analysis}

An experimental total mixed ration was prepared using annual ryegrass, corn oil (C8267, Sigma-Aldrich Co., St. Louis, MO, USA), and LPL, and the chemical compositions of the experimental diets are shown in Table 1. Before chemical analysis was conducted, feed ingredients and experimental diets were dried at $60^{\circ} \mathrm{C}$ for $96 \mathrm{~h}$ and ground through a cyclone mill (Foss Tecator Cyclotec 1093, Foss, Hillerød, Denmark) fitted with a $1 \mathrm{~mm}$ screen. The DM (\#934.01), crude protein (CP, \#976.05), ether extract (EE, \#920.39), acid detergent fiber (\#973.18), and ash (\#942.05) were analyzed by AOAC international methods [11]. The CP was calculated by multiplying the nitrogen content by 6.25 , and total nitrogen was measured using the Kjeldahl method with a nitrogen combustion analyzer (Leco FP-528 Leco, St. Joseph, MI, USA). Neutral detergent fiber (aNDF) and lignin were analyzed [12] to determine the fiber content. Heat-stable amylase ( $a$-amylase) was used to estimate aNDF and was expressed inclusive of residual ash. Non-fibrous carbohydrate (NFC)
Table 1. Estimated chemical composition (\% dry matter basis) of experimental diets used in vitro

\begin{tabular}{lcccc}
\hline \multirow{2}{*}{ Items } & \multicolumn{4}{c}{ Treatments $^{\text {1) }}$} \\
\cline { 2 - 5 } & CON & OiL & LLPL & HLPL \\
\hline DM & 94.80 & 94.46 & 94.46 & 94.46 \\
CP & 1.77 & 1.65 & 1.65 & 1.65 \\
NDF & 75.84 & 70.53 & 70.50 & 70.47 \\
ADF & 48.36 & 44.98 & 44.96 & 44.94 \\
Lignin & 7.65 & 7.11 & 7.11 & 7.11 \\
EE & 1.07 & 7.99 & 7.99 & 7.99 \\
Ash & 6.12 & 5.69 & 5.69 & 5.68 \\
Ca & 0.30 & 0.27 & 0.27 & 0.27 \\
P & 0.08 & 0.08 & 0.08 & 0.08 \\
NFC & 13.67 & 12.71 & 12.75 & 12.78 \\
\hline
\end{tabular}

$\mathrm{DM}$, dry matter; $\mathrm{CP}$, crude protein; NDF, neutral detergent fiber analyzed with heatstable $\boldsymbol{\alpha}$-amylase; $A D F$, acid detergent fiber; $E E$, ether extract; NFC, non-fibrous carbohydrate; LPL, lysophospholipids.

1) CON, annual ryegrass; OiL, 93\% annual ryegrass $+7 \%$ corn oil on a DM basis (an experimental substrate); LLPL, an experimental substrate with $0.08 \%$ DM of LPL; HLPL, an experimental substrate with $0.16 \%$ DM of LPL.

of the experimental diets was estimated as follows:

$$
\mathrm{NFC}=[100-\text { ash }-\mathrm{EE}-\mathrm{CP}-\mathrm{aNDF}] .
$$

\section{Experimental treatments}

A commercial LPL (Lipidol Ultra, Easy Bio Inc., Seoul, Korea) was used in this study as an emulsifier. According to the manufacturer, the LPL is hydrolyzed soy lecithin with the inclusion of phospholipids and free fatty acids. A complete randomized block design was used for the experiment, with treatment as the main effect. Four experimental treatments were used as follows: i) annual ryegrass (CON), ii) $93 \%$ annual ryegrass $+7 \%$ corn oil on a DM basis (OiL), iii) OiL diet supplemented with a low level (0.08\% of dietary DM) of LPL (LLPL), and iv) OiL diet supplemented with a high level $(0.16 \%$ of dietary DM) of LPL (HLPL).

\section{In vitro fermentation}

In vitro fermentation was carried out using the rumen fluid collected from two cannulated Holsteins (body weight [BW] $450 \pm 30 \mathrm{~kg}$ ) before the morning feed at the Center for Agriculture Research, Pusan National University, Korea. Animals were fed a diet consisting of $600 \mathrm{~g} / \mathrm{kg}$ Timothy hay and 400 $\mathrm{g} / \mathrm{kg}$ of a commercial concentrate mix. The rumen fluid was collected before the morning feeding time, mixed, transferred into a thermos bottle, and immediately transported to the laboratory. Rumen content was filtered through four layers of cheesecloth and mixed with $3 \times$ volume of in vitro rumen buffer solution [13] under strictly anaerobic conditions. Approximately $0.5 \mathrm{~g}$ of the ground experimental substrates were placed into pre-weighed nylon bags (R510, Ankom Technology, Fairport, NY, USA). All the bags were heat-sealed and 
transferred into empty $125 \mathrm{~mL}$ serum bottles. Three bottles were used per dietary treatment, and each bottle contained two bags. Then, $70 \mathrm{~mL}$ of rumen fluid and buffer mixture was transferred, accompanied by continuously flushing with $\mathrm{O}_{2}$-free $\mathrm{CO}_{2}$ gas. The bottles were sealed with butyl rubber stoppers and aluminum caps and incubated on a rotary shaker (JSSI-300T, JS Research Inc., Gongju, Korea) at 20 $\mathrm{rpm}$ for $48 \mathrm{~h}$ at $39^{\circ} \mathrm{C}$. After incubation for $48 \mathrm{~h}$, gas production, in vitro DM degradability (IVDMD), in vitro NDF degradability (IVNDFD), $\mathrm{pH}$, ammonia nitrogen $\left(\mathrm{NH}_{3}-\mathrm{N}\right)$, and VFA concentrations were measured. Gas production was measured at $3,6,12,24$, and $48 \mathrm{~h}$ by using a pressure transducer (Sun Bee Instrument Inc., Seoul, Korea) as described by Theodorou et al [14]. Gas production profiles obtained during incubation were fitted to a simple exponential model [15], and the equation is as follows:

$$
\begin{array}{ll}
V_{T}=0 & (0 \leq \mathrm{T} \leq \mathrm{L}), \\
V_{T}=V_{\max } \times\left(1-\mathrm{e}^{[-K g \times(T-L)]}\right) & (\mathrm{T} \geq \mathrm{L}),
\end{array}
$$

where $\mathrm{T}$ is time (h), $\mathrm{L}$ is lag time (h), e is the exponential function, $\mathrm{K}_{\mathrm{g}}$ is the fractional rate of gas production $\left(\mathrm{h}^{-1}\right)$, $\mathrm{V}_{\max }$ is the theoretical maximum gas production $(\mathrm{mL})$ after the asymptote is reached, and $\mathrm{V}_{\mathrm{T}}$ is gas produced at time $\mathrm{T}$ $(\mathrm{mL})$. After incubation, the bottle caps were removed, and the bottles were fixed immediately on ice to stop the fermentation. The nylon bags were then removed from the bottles and rinsed under flowing water until the water ran clear. The washed bags were then dried at $60^{\circ} \mathrm{C}$ for $72 \mathrm{~h}$ and weighed to measure IVDMD. The NDF content of the weighed bags was assessed using a modified version of the micro-NDF method proposed by Pell and Schofield [16] to evaluate the IVNDFD. The $\mathrm{pH}$ of the culture fluid was measured using a pH meter (FP20, Mettler Toledo, Columbus, OH, USA). Sample fluid $(5 \mathrm{~mL})$ was centrifuged at $20,000 \times g$ for $20 \mathrm{~min}$ at $4^{\circ} \mathrm{C}$, the supernatant was discarded, and the pellet was stored at $-80^{\circ} \mathrm{C}$ until rumen microbial population analysis. The remaining culture fluid was then centrifuged at 15,000 $\times g$ for $10 \mathrm{~min}$ at $4^{\circ} \mathrm{C}$ and stored at $-20^{\circ} \mathrm{C}$, until VFA and $\mathrm{NH}_{3}-\mathrm{N}$ analysis.

For the VFA analysis, $200 \mu \mathrm{L}$ of the supernatant was diluted with $800 \mu \mathrm{L}$ of ethyl alcohol anhydrous (4023-2304, Daejung Chemicals, Siheung, Korea) after 15 min of centrifugation at $20,000 \times g$. VFA was measured via gas chromatography (Agilent 7890A, Agilent Technology, Santa Clara, CA, USA) equipped with a flame ionization detector and capillary column $(\mathrm{Nu}-$ kol Fused silica capillary column, $30 \mathrm{~m} \times 250 \mu \mathrm{m} \times 0.25 \mu \mathrm{m}$, Supelco Inc., Bellefonte, PA, USA). The temperature of the oven, injector, and detector was set at $90^{\circ} \mathrm{C}, 90^{\circ} \mathrm{C}$ to $200^{\circ} \mathrm{C}$, and $230^{\circ} \mathrm{C}$, respectively. Nitrogen was used as the carrier gas at a flow rate of $30 \mathrm{~mL} / \mathrm{min}$. The $\mathrm{NH}_{3}-\mathrm{N}$ concentration was analyzed with several modifications [17]. After $2 \mu \mathrm{L}$ of the supernatant was mixed with $100 \mu \mathrm{L}$ of phenol color reagent (50 g of phenol, $0.25 \mathrm{~g}$ of sodium nitroferricyanide, and $1 \mathrm{~L}$ of distilled water) and alkali hypochlorite ( $25 \mathrm{~g}$ of sodium hydroxide, $16.8 \mathrm{~mL}$ of sodium hydroxide, and $1 \mathrm{~L}$ of distilled water), the mixture was incubated in a water bath at $37^{\circ} \mathrm{C}$ for $15 \mathrm{~min}$. The ammonia concentration was determined by measuring the optical density at $630 \mathrm{~nm}$ using a microplate reader (iMARK, Bio-Rad, Hercules, CA, USA).

\section{Total DNA extraction and real-time polymerase chain reaction}

Total DNA was extracted from the pellet stored at $-80^{\circ} \mathrm{C}$ using the repeated bead beating plus column $(\mathrm{RBB}+\mathrm{C})$ method [18]. Genomic DNA was treated with RNase A and proteinase $\mathrm{K}$ and purified using columns from the DokDo-Prep Genomic DNA Kit (Elpis-Biotech, Daejeon, Korea). The concentration and purity of total DNA were measured using a NanoDrop (ND-1000, Thermo Fisher, Waltham, MA, USA).

Real-time polymerase chain reaction (PCR) assays were performed on a CFX 96 Touch system (Bio-Rad Laboratories, Inc., Hercules, CA, USA). Information on primer sequences for rumen microbes was collected from previous studies $[19,20]$ and is presented in Table 2 . Reactions were performed in triplicate, in reaction volumes of $20 \mu \mathrm{L}$, by using optical reaction plates sealed with optical adhesive film. Each reaction mixture contained $0.5 \mu \mathrm{L} 10 \mathrm{mM}$ dNTP Mix (BioFACT, Daejeon, Korea), $2 \mu \mathrm{L} 10 \times$ buffer (BioFACT, Korea), $1 \mu \mathrm{L}$ of genomic DNA diluted 10-fold, $1 \mu \mathrm{L}$ forward primer (10 $\mu \mathrm{M}), 1 \mu \mathrm{L}$ reverse primer $(10 \mu \mathrm{M}), 0.1 \mu \mathrm{L}$ Taq polymerase (BioFACT, Korea), $1 \mu \mathrm{L}$ Evagreen (SolGent Co., Ltd., Daejeon, Korea), and 13.4 $\mu$ L PCR-grade water. Real-time PCR was carried out according to the manufacturer's instructions, as follows: initiation for one cycle at $95^{\circ} \mathrm{C}$ for $10 \mathrm{~min} ; 40$ cycles each for denaturation at $95^{\circ} \mathrm{C}$ for $30 \mathrm{~s}$, annealing at $60^{\circ} \mathrm{C}$ for $30 \mathrm{~s}$, and elongation at $72^{\circ} \mathrm{C}$ for $30 \mathrm{~s}$; and final elongation at $72^{\circ} \mathrm{C}$ for $5 \mathrm{~min}$. Fluorescence was recorded at the end of each denaturation and extension step, and the specificity of the amplicon was confirmed via dissociation curve analysis of PCR end products by increasing the temperature at a rate of $1^{\circ} \mathrm{C}$ every $30 \mathrm{~s}$, from $60^{\circ} \mathrm{C}$ to $95^{\circ} \mathrm{C}$. For absolute quantification of each microbe, standard plasmids containing the respective target gene sequence were obtained by PCR cloning using each primer set described in Table 2. The copy number of each standard primer was calculated [21] and diluted in 10-fold serial dilutions. CFX manager software (Bio-Rad, USA) was used to compare microbe quantifications with the standard curve.

\section{Statistical analysis}

Statistical analyses were performed using the PROC GLIMMIX procedure of SAS 9.3 (SAS Institute Inc., Cary, NC, USA). 
Table 2. Polymerase chain reaction primers used in this study

\begin{tabular}{|c|c|c|c|c|c|}
\hline Target species & Primer & Sequence $\left(5^{\prime} \rightarrow 3^{\prime}\right)$ & Size (bp) & Efficiency $^{1)}$ & References \\
\hline \multirow[t]{2}{*}{ General bacteria } & $\mathrm{F}$ & CGGCAACGAGCGCAACCC & 130 & 1.90 & [19] \\
\hline & $\mathrm{R}$ & CCATTGTAGCACGTGTGTAGCC & & & \\
\hline \multirow[t]{2}{*}{ Ciliate protozoa } & $\mathrm{F}$ & GCTTTCGWTGGTAGTGTATT & 223 & 1.89 & [35] \\
\hline & $R$ & CTTGCCCTCYAATCGTWCT & & & \\
\hline \multirow[t]{2}{*}{ Fungi } & $\mathrm{F}$ & GAGGAAGTAAAAGTCGTAACAAGGTTTC & 120 & 2.10 & [19] \\
\hline & $\mathrm{R}$ & CAAATTCACAAAGGGTAGGATGATT & & & \\
\hline \multirow[t]{2}{*}{ Fibrobacter succinogenes } & $\mathrm{F}$ & GTTCGGAATTACTGGGCGTAAA & 121 & 1.91 & [19] \\
\hline & $\mathrm{R}$ & CGCCTGCCCCTGAACTATC & & & \\
\hline \multirow[t]{2}{*}{ Ruminococcus albus } & $\mathrm{F}$ & CCCTAAAAGCAGTCTTAGTTCG & 176 & 2.02 & [36] \\
\hline & $\mathrm{R}$ & ССTCCTTGCGGTTAGAACA & & & \\
\hline \multirow[t]{2}{*}{ Ruminococcus flavefaciens } & $\mathrm{F}$ & CGAACGGAGATAATTTGAGTTTACTTAGG & 132 & 1.88 & [19] \\
\hline & $\mathrm{R}$ & CGGTCTCTGTATGTTATGAGGTATTACC & & & \\
\hline \multirow[t]{2}{*}{ Butyrivibrio fibrisolvens } & $\mathrm{F}$ & ACCGCATAAGCGCACGGA & 65 & 1.85 & [37] \\
\hline & $\mathrm{R}$ & CGGGTCCATCTTGTACCGATAAAT & & & \\
\hline \multirow[t]{2}{*}{ Butyrivibrio proteoclasticus } & $\mathrm{F}$ & TCCGGTGGTATGAGATGGGC & 185 & 2.07 & [38] \\
\hline & $\mathrm{R}$ & GTCGCTGCATCAGAGTTTCCT & & & \\
\hline \multirow[t]{2}{*}{ Anaerovibrio lipolytica } & $\mathrm{F}$ & TGGGTGTTAGAAATGGATTC & 597 & 1.88 & [39] \\
\hline & $\mathrm{R}$ & CTCTCCTGCACTCAAGAATT & & & \\
\hline
\end{tabular}

bp, base pair.

1) Efficiency is calculated as [10 $\left.10^{-1 / \text { slope }}\right]$.

The fixed effect in this model was a treatment. Orthogonal contrast was used to analyze the difference between OiL and LPL (LLPL and HLPL) treatments, with a linear effect (Lin) when the level of LPL supplementation increased. Differences among treatments were compared using Tukey's range test if a significant effect was observed. Statistical significance was declared at $\mathrm{p}<0.05$, and a trend was speculated at $0.05 \leq$ $\mathrm{p}<0.10$.

\section{RESULTS}

The effects of LPL on gas production and parameters are presented in Table 3 . There was no difference in gas production among treatments until $6 \mathrm{~h}$ incubation. Gas production in $\mathrm{CON}$ was significantly higher at $12 \mathrm{~h}$ incubation and tended to be higher than that in other oil supplementation groups at $24 \mathrm{~h}$ (treatment effect [TRT], $\mathrm{p}=0.004$ and 0.052 , respectively). Although final gas production in CON was significantly higher than that in OiL and LLPL, no difference was observed between CON and HLPL. No significant difference in $\mathrm{V}_{\max }$ and $\mathrm{K}_{\mathrm{g}}$ was detected among treatments (Table 3 ).

There was no significant change in IVDMD, $\mathrm{pH}, \mathrm{NH}_{3}-\mathrm{N}$,

Table 3. Gas production parameters after in vitro incubation of experimental diets using strained rumen fluid

\begin{tabular}{|c|c|c|c|c|c|c|c|c|}
\hline \multirow{2}{*}{ Items } & \multicolumn{4}{|c|}{ Treatments $^{1)}$} & \multirow{2}{*}{ SEM } & \multicolumn{3}{|c|}{$p$-value ${ }^{2)}$} \\
\hline & CON & OiL & LLPL & HLPL & & TRT & OiL-LPL & Lin \\
\hline \multicolumn{9}{|c|}{ Gas (mL/g DM) } \\
\hline $6 \mathrm{~h}$ & 45.4 & 42.9 & 42.8 & 42.9 & 1.08 & 0.119 & 0.936 & 0.972 \\
\hline $12 \mathrm{~h}$ & $74.8^{\mathrm{a}}$ & $70.0^{b}$ & $69.5^{b}$ & $70.2^{b}$ & 1.07 & 0.004 & 0.367 & 0.484 \\
\hline $24 \mathrm{~h}$ & 129.0 & 119.5 & 119.9 & 122.8 & 3.08 & 0.052 & 0.700 & 0.912 \\
\hline \multicolumn{9}{|c|}{ Fitted parameters of gas ${ }^{3)}$} \\
\hline$V_{\max }$ & 267.7 & 246.0 & 252.6 & 259.9 & 9.32 & 0.193 & 0.964 & 0.493 \\
\hline $\mathrm{K}_{\mathrm{g}}$ & 0.028 & 0.029 & 0.028 & 0.027 & 0.0015 & 0.834 & 0.924 & 0.564 \\
\hline
\end{tabular}

SEM, standard error of the mean; DM, dry matter.

1) CON, annual ryegrass; OiL, 93\% annual ryegrass + 7\% corn oil on a dry matter (DM) basis (an experimental substrate); LLPL, an experimental substrate with $0.08 \%$ DM of lysophospholipids (LPL); HLPL, an experimental substrate with $0.16 \%$ DM of LPL.

${ }^{2)}$ TRT, treatment effect; OiL-LPL, OiL vs LPL treatment; Lin, a linear effect of LPL.

${ }^{3)} \mathrm{V}_{\text {max }}$, theoretical maximum gas production $(\mathrm{mL} / \mathrm{g} \mathrm{DM}) ; \mathrm{K}_{\mathrm{g}}$, fractional rate of gas production $\left(\mathrm{h}^{-1}\right)$.

$a, b$ Values in the same row with different letters differ significantly $(p<0.05)$. 
Table 4. Fermentation characteristics after in vitro incubation of experimental diets using strained rumen fluid

\begin{tabular}{|c|c|c|c|c|c|c|c|c|}
\hline \multirow{2}{*}{ Items } & \multicolumn{4}{|c|}{ Treatments $^{1)}$} & \multirow{2}{*}{ SEM } & \multicolumn{3}{|c|}{ p-value ${ }^{2)}$} \\
\hline & CON & OiL & LLPL & HLPL & & TRT & OiL-LPL & Lin \\
\hline $\operatorname{IVDMD~(\% )~}$ & 63.0 & 63.6 & 62.7 & 63.4 & 0.68 & 0.625 & 0.177 & 0.177 \\
\hline IVNDFD (\%NDF) & $61.3^{\mathrm{a}}$ & $58.9^{b}$ & $58.3^{b}$ & $58.8^{b}$ & 0.65 & 0.007 & 0.315 & 0.310 \\
\hline $\mathrm{pH}$ & 6.7 & 6.6 & 6.5 & 6.5 & 0.07 & 0.821 & 0.539 & 0.302 \\
\hline $\mathrm{NH}_{3}-\mathrm{N}(\mathrm{mg} / 100 \mathrm{~mL})$ & 38.3 & 37.7 & 37.9 & 37.9 & 0.99 & 0.951 & 0.876 & 0.829 \\
\hline TVFA (mM) & 64.6 & 63.4 & 62.3 & 63.3 & 0.97 & 0.229 & 0.330 & 0.372 \\
\hline $\mathrm{C} 2(\mathrm{mmol} / \mathrm{mol})$ & $605.9^{\mathrm{a}}$ & $589.5^{b}$ & $591.4^{b}$ & $593.5^{b}$ & 2.07 & $<0.001$ & 0.984 & 0.414 \\
\hline C3 (mmol/mol) & $235.3^{b}$ & $251.4^{\mathrm{a}}$ & $245.7^{\mathrm{a}}$ & $245.5^{\mathrm{a}}$ & 2.34 & $<0.001$ & 0.240 & 0.057 \\
\hline C4 (mmol/mol) & $101.0^{\mathrm{ab}}$ & $99.7^{b}$ & $102.2^{\mathrm{a}}$ & $100.9^{\mathrm{ab}}$ & 0.52 & 0.010 & 0.007 & 0.004 \\
\hline iso-C4 (mmol/mol) & 11.1 & 11.0 & 11.0 & 10.9 & 0.09 & 0.151 & 0.170 & 0.641 \\
\hline C5 $(\mathrm{mmol} / \mathrm{mol})$ & $26.4^{b}$ & $27.9^{\mathrm{a}}$ & $28.9^{\mathrm{a}}$ & $28.7^{\mathrm{a}}$ & 0.38 & $<0.001$ & $<0.001$ & $<0.001$ \\
\hline iso-C5 (mmol/mol) & $20.3^{b}$ & $20.5^{\mathrm{ab}}$ & $20.8^{\mathrm{a}}$ & $20.5^{a b}$ & 0.13 & 0.032 & 0.021 & 0.037 \\
\hline A:P ratio & $2.6^{\mathrm{a}}$ & $2.3^{b}$ & $2.4^{\mathrm{b}}$ & $2.4^{b}$ & 0.03 & $<0.001$ & 0.363 & 0.105 \\
\hline
\end{tabular}

SEM, standard error of the mean; IVDMD, in vitro dry matter degradability; IVNDFD, in vitro neutral detergent fiber degradability; $\mathrm{NH}_{3}-\mathrm{N}$, ammonia nitrogen; TVFA, total volatile fatty acids; $\mathrm{C2}$, acetate; $\mathrm{C}$, propionate; $\mathrm{C} 4$, butyrate; iso- $\mathrm{C} 4$, iso butyrate; $\mathrm{C}$, valerate; iso- $\mathrm{C}$, iso valerate; $\mathrm{A}: \mathrm{P}$ ratio, acetate to propionate ratio.

1) CON, annual ryegrass; OiL, $93 \%$ annual ryegrass + 7\% corn oil on a dry matter (DM) basis (an experimental substrate); LLPL, an experimental substrate with $0.08 \%$ DM of lysophospholipids (LPL); HLPL, an experimental substrate with $0.16 \%$ DM of LPL.

${ }^{2)}$ TRT, treatment effect; OiL-LPL, OiL vs LPL treatment; Lin, a linear effect of LPL.

$a, b$ Values in the same row with different letters differ significantly $(p<0.05)$.

and VFA production among all treatments (Table 4), whereas corn oil supplementation had a negative effect on IVNDFD (TRT, $\mathrm{p}=0.007$ ). Regarding the proportion of individual VFAs, oil supplementation significantly decreased the proportion of acetate and the acetate to propionate $(\mathrm{A}: \mathrm{P})$ ratio (both, $\mathrm{p}<0.001$ ) and increased the proportion of propionate, valerate, iso-valerate (TRT, $\mathrm{p}<0.0001,<0.0001$, and $=0.032$, respectively). Propionate proportion tended to decrease with increasing levels of LPL supplementation (Lin, $p=0.057$ ), although there was no significance in the proportion of acetate and iso-butyrate. LPL supplementation significantly increased the proportion of butyrate (OiL vs LPL, $p=0.007$; Lin, $p=$ 0.004 ), valerate (OiL vs $L P L, p<0.001$; Lin, $p<0.001$ ), and iso-valerate (OiL vs LPL, $\mathrm{p}=0.021$; Lin, $\mathrm{p}=0.037$ ). The A:P ratio numerically increased with increasing levels of LPL supplementation (Lin, $\mathrm{p}=0.105$ ).

Regarding the microbial counts, although there was no significant change in the absolute value of total bacteria among treatments, LPL supplementation tended to increase total bacteria in a linear manner (Lin, $p=0.089$ ) compared to OiL (Table 5). Absolute counts of ciliate protozoa and Fungi were not changed by oil supplementation among treatments,

Table 5. Microbial abundance after in vitro incubation of experimental diets using strained rumen fluid

\begin{tabular}{|c|c|c|c|c|c|c|c|c|}
\hline \multirow{2}{*}{ Items } & \multicolumn{4}{|c|}{ Treatments $^{1)}$} & \multirow{2}{*}{ SEM } & \multicolumn{3}{|c|}{ p-value ${ }^{2)}$} \\
\hline & CON & OiL & LLPL & HLPL & & TRT & OiL-LPL & Lin \\
\hline \multicolumn{9}{|l|}{ Absolute abundance ${ }^{3)}$} \\
\hline Total bacteria & 4.7 & 3.9 & 4.3 & 4.2 & 0.44 & 0.318 & 0.120 & 0.089 \\
\hline Ciliate protozoa & 8.2 & 6.2 & 7.5 & 7.2 & 1.41 & 0.502 & 0.409 & 0.252 \\
\hline Fungi & 7.6 & 3.7 & 2.7 & 3.9 & 2.08 & 0.136 & 0.048 & 0.150 \\
\hline \multicolumn{9}{|c|}{ Relative proportion, \% total bacteria } \\
\hline Fibrobacter succinogenes & $27.3^{\mathrm{a}}$ & $19.0^{\mathrm{ab}}$ & $9.0^{b}$ & $12.6^{b}$ & 4.14 & 0.008 & 0.094 & 0.028 \\
\hline Ruminococcus albus & $10.4^{\mathrm{a}}$ & $6.7^{b}$ & $5.3^{b}$ & $6.0^{b}$ & 0.51 & $<0.001$ & 0.011 & 0.006 \\
\hline Ruminococcus flavefaciens & $0.29^{\mathrm{a}}$ & $0.20^{b}$ & $0.17^{b}$ & $0.18^{b}$ & 0.020 & 0.001 & 0.178 & 0.102 \\
\hline Butyrivibrio fibrisolvens & 0.37 & 0.34 & 0.34 & 0.29 & 0.034 & 0.208 & 0.573 & 0.933 \\
\hline Anaerovibrio lipolytica & $0.13^{c}$ & $0.67^{\mathrm{a}}$ & $0.48^{b}$ & $0.42^{b}$ & 0.035 & $<0.001$ & 0.099 & 0.003 \\
\hline Butyrivibrio proteoclasticus & $13.1^{b}$ & $29.7^{a}$ & $16.6^{b}$ & $20.3^{b}$ & 2.91 & 0.002 & 0.024 & 0.003 \\
\hline
\end{tabular}

SEM, standard error of the mean.

1) CON, annual ryegrass; OiL, 93\% annual ryegrass + 7\% corn oil on a dry matter (DM) basis (an experimental substrate); LLPL, experimental substrate with $0.08 \%$ DM of lysophospholipids (LPL); HLPL, experimental substrate with $0.16 \%$ DM of LPL.

${ }^{2)}$ TRT, treatment effect; OiL-LPL, OiL vs LPL treatments; Lin, linear effect of LPL.

${ }^{3)}$ Total bacteria, $\times 10^{10}$ copies $/ \mathrm{mL}$ of rumen fluid; Ciliate protozoa, $\times 10^{8}$ copies $/ \mathrm{mL}$ of rumen fluid; Fungi, $\times 10^{6}$ copies $/ \mathrm{mL}$ of rumen fluid.

$a, b$ Values in the same row with different letters differ significantly $(p<0.05)$. 
but Fungi was affected by LPL treatment (OiL-LPL, p = 0.048). In the relative proportion of each bacteria, fiber degrading bacteria (Fibrobacter succinogenes [F. succinogenes], Ruminococcus albus [R. albus], and Ruminococcus flavefaciens $[R$. flavefaciens] ) was decreased by oil supplementation (TRT, F. succinogenes, $\mathrm{p}=0.008 ; R$. albus, $\mathrm{p}<0.001$; and $R$. flavefaciens, $\mathrm{p}=0.001)$. The relative proportion of $F$. succinogenes and $R$. albus was significantly decreased in a linear manner by LPL supplementation (Lin, F. succinogenes, $\mathrm{p}=0.028 ; R$. albus, $\mathrm{p}=0.006)$. There was no significant change in Butyrivibrio fibrisolvens, whereas oil supplementation resulted in a significantly higher proportion of Anaerovibrio lipolytica (A. lipolytica) than that in the CON group (TRT, $\mathrm{p}<0.001$ ). The highest proportion of Butyrivibrio proteoclasticus (B. proteoclasticus) was observed in the OiL group (TRT, $\mathrm{p}=0.002$ ), and LPL supplementation resulted in lower relative proportions of $B$. proteoclasticus and A. lipolytica than that in the OiL group (Lin, B. proteoclasticus, $\mathrm{p}=$ 0.003; A. lipolytica, $\mathrm{p}=0.003$ ).

\section{DISCUSSION}

Oil supplementation can change rumen fermentation characteristics and decrease nutrient digestibility, which is mainly induced by a shift of microbial diversity $[22,23]$. Hence, the effect of fat supplementation on rumen fermentation is varied depending on the type and saturation of fat and the type of diets [23,24]. Matsuba et al [22] observed that supplementing $5 \% \mathrm{DM}$ of soybean and coconut oils and 7.5\% DM of palm oil had a negative influence on the proportion of $F$ succinogenes during in vitro rumen fermentation. Jenkins [25] suggested that the inclusion of fat in the rumen could have antimicrobial effects and also coat the feed particles, thereby inhibiting digestibility. The results from the present study showed that substituting 7\% DM with corn oil in forage significantly decreased the proportion of fibrolytic bacteria (F. succinogenes and $R$. albus) and IVNDFD.

Previous studies have shown that the main positive effects of LPL supplementation on nonruminant animals were increase of apparent nutrient digestibility, thereby improving feed efficiency $[4,6]$. Conversely, Jenkins et al [7] reported that supplementation of lecithin ( $2 \%$ to $6 \%$ of dietary DM) decreased NDF and OM digestibility during in vitro rumen fermentation. Lee et al [9] also reported that LPL supplementation tended to decrease the apparent digestibility of DM and $\mathrm{OM}$ and induced a numerical decrease in the apparent digestibility of NDF, although they observed an increased milk yield resulting in increased feed efficiency. Considering the results of previous studies on ruminant, the effects of LPL as an emulsifier is unclear in the general ruminant diet. In addition, oil supplementation is one of the alternative strategies to increase energy density of diet when ruminant animal required high energy [22]. Therefore, in this study, we focused on the emulsifying ability of LPL on the rumen ecosystem when the ruminant diet was supplemented with a high lipid content. We hypothesized that LPL supplementation could prevent the negative effects of oil supplementation by emulsification of the supplemented oil. Contrary to our expectations, in the present study, there were no effects on total gas production and/or on the degradability of DM and NDF in vitro between OiL versus LPL groups; even the relative proportions of several cellulolytic bacteria (F. succinogenes and $R$. albus) significantly reduced with increasing levels of LPL supplementation. Lee et al [10] reported that Tween 80 (type of emulsifier) significantly increased the in situ DM disappearance in rice straw, although the emulsifier reduced the attachment of major rumen cellulolytic bacteria (F. succinogenes, $R$. albus, and $R$. flavefaciens). Similarly, Kamande et al [26] stated that the use of emulsifiers (Tween 60 and Tween 80 ) might enhance rumen microbial cellulase activities, inducing an increase in cellulose degradation rather than improving the attachment ability of fibrolytic bacteria. Considering previous results, it is possible that LPL supplementation could increase the enzymatic activity of cellulolytic bacteria similar to that by other emulsifiers (Tween 60 and Tween 80 ) in the rumen under high lipid conditions.

In the present study, oil supplementation decreased the proportion of acetate and A:P ratio and increased the proportion of propionate in total VFA; however, the total VFA concentration did not change. Getachew et al [27] reported an increase in propionate production and decrease in acetate production and A:P ratio with supplementation of corn oil in an in vitro system. Similarly, Pi et al [28] also observed that supplementation of $4 \%$ rubber seed oil and flaxseed oil significantly increased the proportion of propionate, whereas it decreased the proportion of acetate in dairy cattle. Generally, lipid sources entering the rumen are degraded into glycerol, sugars, and free fatty acids through hydrolysis of ester linkages by rumen lipolytic bacteria (e.g. A. lipolytica, B. fibrisolvens, and $B$. proteoclasticus) [29]. In the present study, oil supplementation significantly increased the relative proportion of A. lipolytica, one of the major rumen bacteria related to lipid hydrolysis, which might then increase glycerol and sugar that can be metabolized to VFA. It was previously reported that glycerol supplemented in the rumen could increase proportion of propionate at the expense of acetate proportion [30]. In addition, corn oil had high proportion of unsaturated fatty acids, and the unsaturated fatty acids could negatively affect ruminal fibrolytic bacteria, thereby decreasing A:P ratio [31]. Thus, we suggested that the changes between acetate and propionate proportion might be related to improved lipid hydrolysis.

In this study, LPL supplementation increased the proportion of butyrate, valerate, and iso-valerate but tended to 
decrease that of propionate. Considering that glycerol which is one of the main products in lipid metabolism could be fermented into propionate, butyrate, valerate, and isovalerate rather than acetate [32], LPL supplementation might affect glycerol fermentation pathway in the rumen. Few studies have investigated the effects of LPL on the characteristics of rumen fermentation. Jenkins et al [7] reported that increasing levels of purified phospholipids $(0,10,20$, and $30 \mathrm{mg})$ increased the proportion of propionate in a linear manner without a negative effect on the total VFA during in vitro fermentation. Sontakke et al [8] observed no significant changes in the production of acetate, propionate, and butyrate in vitro when LPL extracted from rice bran was supplemented up to $10 \%$ in the ration. Lee et al [9] observed an increased proportion of valerate and decreased proportions of acetate and A:P ratio in dairy cattle. Lee et al [9] also reported that the effect of LPL can vary depending on the different products of LPL, because the proportion of LPL differs based on the sources and enzymatic hydrolysis of phospholipids. However, the discrepancy in individual VFAs between the findings of Lee et al [9] and those of the present study is difficult to explain, because the same LPL product was used. This may be partially explained by the higher dosage of LPL in the current study (HLPL, $0.16 \%$ of DM) compared to that used by Lee et al [9] (HLPL, $0.075 \%$ of DM). In addition, we supplemented a high dosage of corn oil in the forage diet, which might have influenced the effects of LPL on rumen fermentation.

Supplementation of LPL significantly reduced the relative proportion of lipid-utilizing bacteria (A. lipolytica and $B$. proteoclasticus), which might decrease lipid digestion (hydrolysis and biohydrogenation) in the rumen. This finding is similar to that of Rico et al [33] who reported that lysolecithin may inhibit the hydrolysis and biohydrogenation of the lipid source in the rumen. Polycarpo et al [34] observed that supplementation of LPL could decrease the count of grampositive cocci in the jejunum of broilers when fed a corn-based diet containing beef tallow. These authors also speculated that LPL might exert an antimicrobial effect on the gram-positive microorganisms by changing the cell membrane permeability. In the present study, LPL supplementation negatively affected the proportions of several gram-positive bacteria ( $R$. albus, $R$. flavefaciens, and B. proteoclasticus), as well as gram-negative bacteria (F. succinogenes and A. lipolytica), whereas the total bacterial counts tended to increase in a linear manner. Therefore, it is thought that LPL supplementation could be effective as an antimicrobial agent rather than as an emulsifier in the rumen.

\section{CONCLUSION}

In this study, LPL supplementation had antimicrobial effects on cellulolytic (F. succinogenes and R. albus) and lipolytic (A. lipolytica and B. proteoclasticus) bacteria, with no significant difference in nutrient degradability (DM and NDF). Therefore, use of LPL may be an effective antimicrobial agent for ruminant animal which needed high energy diet. Further studies are needed to evaluate the effects of LPL supplementation on lipid utilization (hydrolysis and biohydrogenation) in the rumen and availability of a lipid source in the small intestine.

\section{CONFLICT OF INTEREST}

We certify that there is no conflict of interest with any financial organization regarding the material discussed in the manuscript. Inhyuk Kwon is an employee of EASY BIO, Inc..

\section{ACKNOWLEDGMENTS}

This research was a part of the project titled 'Yeongnam Sea Grant', funded by the Ministry of Oceans and Fisheries, Korea (1525009968).

\section{REFERENCES}

1. Beauchemin KA, Kreuzer M, O'Mara F, McAllister TA. Nutritional management for enteric methane abatement: a review. Aust J Exp Agric 2008;48:21-7. https://doi.org/10.1071/EA 07199

2. Joshi A, Paratkar SG, Thorat BN. Modification of lecithin by physical, chemical and enzymatic methods. Eur J Lipid Sci Technol 2006;108:363-73. https://doi.org/10.1002/ejlt. 200600016

3. Boontiam W, Jung B, Kim YY. Effects of lysophospholipid supplementation to lower nutrient diets on growth performance, intestinal morphology, and blood metabolites in broiler chickens. Poult Sci 2017;96:593-601. https://doi.org/10.3382/ ps/pew269

4. Polycarpo GV, Burbarelli MFC, CarÃo ACP, et al. Effects of lipid sources, lysophospholipids and organic acids in maizebased broiler diets on nutrient balance, liver concentration of fat-soluble vitamins, jejunal microbiota and performance. Br Poult Sci 2016;57:788-98. https://doi.org/10.1080/000716 68.2016.1219019

5. Zampiga M, Meluzzi A, Sirri F. Effect of dietary supplementation of lysophospholipids on productive performance, nutrient digestibility and carcass quality traits of broiler chickens. Ital J Anim Sci 2016;15:521-8. https://doi.org/10.1080/182805 1X.2016.1192965

6. Zhao PY, Li HL, Hossain MM, Kim IH. Effect of emulsifier (lysophospholipids) on growth performance, nutrient digestibility and blood profile in weanling pigs. Anim Feed Sci Technol 2015;207:190-5. https://doi.org/10.1016/j.anifeed sci.2015.06.007 
7. Jenkins TC, Gimenez T, Cross DL. Influence of phospholipids on ruminal fermentation in vitro and on nutrient digestion and serum lipids in sheep. J Anim Sci 1989;67:529-37. https:// doi.org/10.2527/jas1989.672529x

8. Sontakke UB, Kaur H, Tyagi AK, et al. In vitro evaluation of rice bran lyso-phospholipids for its use in ruminant ration. Indian J Anim Nutr 2014;31:65-8.

9. Lee C, Morris DL, Copelin JE, Hettick JM, Kwon IH. Effects of lysophospholipids on short-term production, nitrogen utilization, and rumen fermentation and bacterial population in lactating dairy cows. J Dairy Sci 2019;102:3110-20. https:// doi.org/10.3168/jds.2018-15777

10.Lee CH, Sung HG, Eslami M, et al. Effects of Tween 80 pretreatment on dry matter disappearance of rice straw and cellulolytic bacterial adhesion. Asian-Australas J Anim Sci 2007;20:1397-401. https://doi.org/10.5713/ajas.2007.1397

11.AOAC. Official Methods of Analysis of AOAC International. 18 ed. Gaithersburg, MD, USA: Association of Official Analytical Chemists International; 2005.

12. Van Soest PJ, Robertson JB, Lewis BA. Methods for dietary fiber, neutral detergent fiber, and nonstarch polysaccharides in relation to animal nutrition. J Dairy Sci 1991;74:3583-97. https://doi.org/10.3168/jds.S0022-0302(91)78551-2

13. Goering HK, Van Soest PJ. Forage fiber analyses (apparatus, reagents, prcedures, and some applications). Washington, DC, USA: USDA Agr Handb; 1970.

14. Theodorou MK, Williams BA, Dhanoa MS, McAllan AB, France J. A simple gas production method using a pressure transducer to determine the fermentation kinetics of ruminant feeds. Anim Feed Sci Technol 1994;48:185-97. https:// doi.org/10.1016/0377-8401(94)90171-6

15. Schofield P, Pitt RE, Pell AN. Kinetics of fiber digestion from in vitro gas production. J Anim Sci 1994;72:2980-91. https:// doi.org/10.2527/1994.72112980x

16. Pell AN, Schofield P. Computerized monitoring of gas production to measure forage digestion in vitro. J Dairy Sci 1993;76:1063-73. https://doi.org/10.3168/jds.S0022-0302 (93)77435-4

17. Chaney AL, Marbach EP. Modified reagents for determination of urea and ammonia. Clin Chem 1962;8:130-2. https:// doi.org/10.1093/clinchem/8.2.130

18. Yu Z, Morrison M. Improved extraction of PCR-quality community DNA from digesta and fecal samples. Biotechniques 2004;36:808-12. https://doi.org/10.2144/04365ST04

19.Denman SE, McSweeney CS. Development of a real-time PCR assay for monitoring anaerobic fungal and cellulolytic bacterial populations within the rumen. FEMS Microbiol Ecol 2006;58:572-82. https://doi.org/10.1111/j.1574-6941. 2006.00190.x

20. Khafipour E, Li S, Plaizier JC, Krause DO. Rumen microbiome composition determined using two nutritional models of subacute ruminal acidosis. Appl Environ Microbiol 2009;75:
7115-24. https://doi.org/10.1128/AEM.00739-09

21. Whelan JA, Russell NB, Whelan MA. A method for the absolute quantification of cDNA using real-time PCR. J Immunol Methods 2003;278:261-9. https://doi.org/10.1016/S00221759(03)00223-0

22. Matsuba K, Padlom A, Khongpradit A, et al. Selection of plant oil as a supplemental energy source by monitoring rumen profiles and its dietary application in Thai crossbred beef cattle. Asian-Australas J Anim Sci 2019;32:1511-20. https:// doi.org/10.5713/ajas.18.0946

23. Rodrigues JPP, Ramin M, Huhtanen P, Aru F, Detmann E, Marcondes MI. Effect of soya bean oil supplementation and forage type on methane production and fibre digestibility using the in vitro gas production system. Grass Forage Sci 2018;73:368-80. https://doi.org/10.1111/gfs.12326

24. Brooks CC, Garner GB, Gehrke CW, Muhrer ME, Pfander $\mathrm{WH}$. The effect of added fat on the digestion of cellulose and protein by ovine rumen microorganisms. J Anim Sci 1954;13: 758-64. https://doi.org/10.2527/jas1954.134758x

25.Jenkins TC. Lipid metabolism in the rumen. J Dairy Sci 1993; 76:3851-63. https://doi.org/10.3168/jds.S0022-0302(93)77 727-9

26. Kamande GM, Baah J, Cheng K-J, McAllister TA, Shelford JA. Effects of Tween 60 and Tween 80 on protease activity, thiol group reactivity, protein adsorption, and cellulose degradation by rumen microbial enzymes. J Dairy Sci 2000;83: 536-42. https://doi.org/10.3168/jds.S0022-0302(00)74913-7

27.Getachew $G$, DePeters EJ, Robinson PH, Taylor SJ. In vitro rumen fermentation and gas production: influence of yellow grease, tallow, corn oil and their potassium soaps. Anim Feed Sci Technol 2001;93:1-15. https://doi.org/10.1016/S03778401(01)00264-4

28. Pi Y, Ma L, Pierce KM, Wang HR, Xu JC, Bu DP. Rubber seed oil and flaxseed oil supplementation alter digestion, ruminal fermentation and rumen fatty acid profile of dairy cows. Animal 2019;13:2811-20. https://doi.org/10.1017/S175173111900137X

29. Bauman D, Perfield J, De Veth M, Lock A. New perspectives on lipid digestion and metabolism in ruminants. In: Proc. Cornell Nutr. Conf; 2003: Cornell University NY, USA. p. 175-89.

30. Rémond B, Souday E, Jouany JP. In vitro and in vivo fermentation of glycerol by rumen microbes. Anim Feed Sci Technol 1993;41:121-32. https://doi.org/10.1016/0377-8401(93)90 $118-4$

31.Yang SL, Bu DP, Wang JQ, et al. Soybean oil and linseed oil supplementation affect profiles of ruminal microorganisms in dairy cows. Animal 2009;3:1562-9. https://doi.org/10.1017/ S1751731109990462

32.El-Nor SA, AbuGhazaleh AA, Potu RB, Hastings D, Khattab MSA. Effects of differing levels of glycerol on rumen fermentation and bacteria. Anim Feed Sci Technol 2010;162:99-105. https://doi.org/10.1016/j.anifeedsci.2010.09.012 
33. Rico DE, Ying Y, Harvatine KJ. Effects of lysolecithin on milk fat synthesis and milk fatty acid profile of cows fed diets differing in fiber and unsaturated fatty acid concentration. J Dairy Sci 2017;100:9042-7. https://doi.org/10.3168/jds.2017-12976

34.Polycarpo GV, Burbarelli MFC, Carao ACP, et al. Effects of lipid sources, lysophospholipids and organic acids in maizebased broiler diets on nutrient balance, liver concentration of fat-soluble vitamins, jejunal microbiota and performance. Br Poult Sci 2016;57:788-98. https://doi.org/10.1080/000716 68.2016.1219019

35.Sylvester JT, Karnati SKR, Yu Z, Morrison M, Firkins JL. Development of an assay to quantify rumen ciliate protozoal biomass in cows using real-time PCR. J Nutr 2004;134:337884. https://doi.org/10.1093/jn/134.12.3378

36. Wang R-F, Cao W-W, Cerniglia CE. PCR detection of Ruminococcus spp. in human and animal faecal samples. Mol Cell Probes 1997;11:259-65. https://doi.org/10.1006/mcpr.1997.
0111

37.Stevenson DM, Weimer PJ. Dominance of Prevotella and low abundance of classical ruminal bacterial species in the bovine rumen revealed by relative quantification real-time PCR. Appl Microbiol Biotechnol 2007;75:165-74. https:// doi.org/10.1007/s00253-006-0802-y

38. Paillard D, McKain N, Chaudhary LC, et al. Relation between phylogenetic position, lipid metabolism and butyrate production by different Butyrivibrio-like bacteria from the rumen. Antonie van Leeuwenhoek 2007;91:417-22. https:/doi.org/ 10.1007/s10482-006-9121-7

39. Tajima K, Aminov RI, Nagamine T, Matsui H, Nakamura M, Benno Y. Diet-dependent shifts in the bacterial population of the rumen revealed with real-time PCR. Appl Environ Microbiol 2001;67:2766-74. http://doi.org/10.1128/AEM.67. 6.2766-2774.2001 